those compliant with health authority (HSE) guidance (OR $0.47,95 \% \mathrm{Cl}: 0.25$, 0.89). Adherence to RMD medications was reported in $84.1 \%$, with $57.1 \%$ using health authority guidelines for information on medication use. Importantly, adherence rates were higher amongst those who cited guidelines $(89.3 \%$ vs $79.9 \%$, $\mathrm{P}<0.001)$, and conversely lower in those with COVID-19 symptoms $(64.0 \%$ vs $85.1 \%, P=0.009$ ). Finally, the use of virtual clinics was supported by $70.4 \%$ of respondents.

Conclusion: The rate of COVID-19 positivity in RMD patients was similar to the general population. COVID-19 symptoms were lower amongst respondents on immunosuppressive medication and those adherent to medication guidelines. Respondents were supportive of HSE advice and virtual rheumatology clinics. Disclosure of Interests: Kieran Murray Grant/research support from: Bresnihan Molloy and Newman fellowships, Sean Quinn: None declared, Matthew Turk: None declared, Anna O'Rourke: None declared, Eamonn Molloy: None declared, Lorraine O'Neill: None declared, Anne Barbara Mongey: None declared, Ursula Fearon: None declared, Douglas Veale: None declared. DOI: 10.1136/annrheumdis-2021-eular.2579

\section{POS1217 THE PATTERN OF COVID 19 PANDEMIC AMONG PATIENTS WITH AUTOIMMUNE INFLAMMATORY RHEUMATIC DISEASES (AIIRD)}

F. Kharouf ${ }^{1}$, T. Eviatar ${ }^{2}$, M. Braun ${ }^{3}$, E. Pokroy-Shapira ${ }^{4}$, M. Brodavka ${ }^{5}$ N. Agmon-Levin ${ }^{6}$, K. Toledano ${ }^{7}$, S. Oren ${ }^{4}$, M. Lidar ${ }^{5}$, Y. Tavor ${ }^{7}$, M. Amit Vazina $^{8}$, F. Sabbah ${ }^{9}$, G. Breuer ${ }^{10}$, A. Dagan ${ }^{11}$, D. Zisman ${ }^{12}$, D. Markovits ${ }^{7}$, T. Reitblat ${ }^{13}$, S. Giryes ${ }^{7}$, D. Mevorach ${ }^{1}$, D. Paran ${ }^{2}$, O. Elkayam ${ }^{2}$, A. BalbirGurman ${ }^{7}$, Y. Braun-Moscovici ${ }^{7}{ }^{1}$ Hadassah Medical Center, Hebrew University of Jerusalem, Rheumatology, Jerusalem, Israel; ${ }^{2}$ Tel Aviv Medical Center, Sackler School of Medicine, Tel Aviv University, Rheumatology, Tel Aviv-Yafo, Israel; ${ }^{3} \mathrm{Hadassah}$ Medical Center, Hebrew University of Jerusalem, Faculty of Medicine, Jerusalem, Israel; ${ }^{4}$ Beilinson Hospital, Sackler School of Medicine, Tel Aviv University, Rheumatology, Petach Tikva, Israel; ${ }^{5}$ Sheba Medical Center, Sackler School of Medicine, Tel Aviv University, Rheumatology, Tel Hashomer, Israel; ${ }^{6}$ Sheba Medical Center, Sackler School of Medicine, Tel Aviv University, Allergy and Clinical Immunology Unit, Tel Hashomer, Israel; ${ }^{7}$ Rambam Health Care Campus, Rappaport Faculty of Medicine, Technion-Israeli Institute of Technology, Rheumatology, Haifa, Israel; ${ }^{8}$ Shamir Medical Center, Sackler School of Medicine, Tel Aviv University, Rheumatology Unit, Beer Yaakov, Israel; ${ }^{9}$ Padeh Poriya, Rheumatology, Tiberias, Israel; ${ }^{10}$ Shaare Zedek Medical Center, Hebrew University of Jerusalem, Rheumatology, Jerusalem, Israel; ${ }^{11}$ Assuta Ashdod Medical Center, Ben Gurion University of the Negev, Rheumatology, Ashdod, Israel; ${ }^{12}$ Carmel Medical Center, Rappaport Faculty of Medicine, Technion-Israeli Institute of Technology, Rheumatology, Haifa, Israel; ${ }^{13}$ Barzilai Medical Center, Ben Gurion University of the Negev, Rheumatology, Ashkelon, Israel

Background: The epidemiology of COVID19 among patients with AIIRD may be influenced by a dysregulated immune system, immunosuppressive therapies and behavioral patterns. Data regarding the epidemiology of COVID19 among patients with AllRD is scarce.

Objectives: To assess the pattern of COVID19 pandemic among patients with AlIRD compared to the general population in Israel

Methods: At the beginning of the COVID-19 pandemic, we established a national registry of patients with AIIRD, diagnosed with COVID-19, based on voluntary reporting by the treating rheumatologist. All the members of the Israeli Society of Rheumatology were encouraged to participate and repeatedly reminded to report any new cases. Rheumatology centers from 11 hospitals from the Northern and Central part of Israel participated in this study. The registry included demographic data, AIIRD diagnosis and duration, systemic organ involvement, co-morbidities, treatment (conventional synthetic disease modifying drugs (csDMARDs), biologic/targeted (b/ts) DMARDs, corticosteroids use, dose and treatment duration, date of COVID19 diagnosis, severity of the viral disease and complications, duration of hospitalization, if required, treatment for COVID 19, laboratory results and outcome. The diagnosis of COVID 19 was made by a positive SARS CoV2 PCR. The indications for SARS CoV2 PCR testing in Israel comprise clinical symptoms or exposure to a confirmed close contact. Severe illness was defined by $\mathrm{SpO}_{2}<94 \%$ in room air, respiratory rate of $>30$ breaths $/ \mathrm{min}, \mathrm{PaO}_{2} / \mathrm{FiO}_{2}<300 \mathrm{~mm} \mathrm{Hg}$, or lung infiltrates $>50 \%$ on chest imaging.

The epidemiological data regarding the number of COVID19 confirmed patients, the number of severe cases and the rate of mortality among the general population per day and per week, were extracted from the data dashboard of the Israeli Ministry of Health. We analyzed data from 02.2020 to 15.01 .2021 .

Results: During the study period we experienced 3 waves of COVID 19 pandemic. The governmental management of COVID19 spread, at the beginning of the pandemic, included inforcement of severe travel restrictions and social distancing, followed eventually by a preventive lockdown, in spite of the relatively low number of cases. Easing of the restrictions, lifting the travel ban, opening of the commerce and schools led to 2 much more severe waves, which triggered 2 new lockdowns. Up to January 2021, 549763 Israelis had confirmed COVID19, 30\% of whom had severe disease, $0.84 \%$ died ( $30 \%$ of the patients with severe disease) We identified 190 AlIRD patients (mean(SD) age 52(18), 30\% males) who had confirmed COVID19. The weekly incidence curve of patients with rheumatic diseases correlated with the curve of the general population (Figure 1).

Sixty-one $\%$ of the patients with AllRD received csDMARDs, $41 \%$ were on b/ tsDMARDs, $39 \%$ on chronic corticosteroids, $12 \%$ on $\geq 10 \mathrm{mg}$ prednisone. Forty-seven $\%$ of patients required hospitalization, 20\% had severe COVID19. Sixteen patients (42\% of patients with severe COVID19) (mean(SD), median age 64.7(15.4),67)) died (systemic sclerosis-4 patients, rheumatoid arthritis - 6, systemic lupus erythematosus -2 , antiphospholipid syndrome-2, granulomatous polyangiitis -1 , polymyalgia rheumatica-1). The AllRD was active in $56 \%$ of them, $50 \%$ received csDMARDs, none of them were on b/tsDMARDs, $31 \%$ received chronic prednisone $>10 \mathrm{mg}$. All patients who died had at least 2 comorbidities. Conclusion: The pattern of spread of COVID19 in AIIRD patients is similar to the general population despite repeated mass media alerts for enhanced social distancing for elderly and immune suppressed patients. The disease tends to be more severe with enhanced mortality, especially in those with active AIIRD disease and organ involvement (lungs, heart, renal), older age and co-morbidities. A reporting bias cannot be excluded.

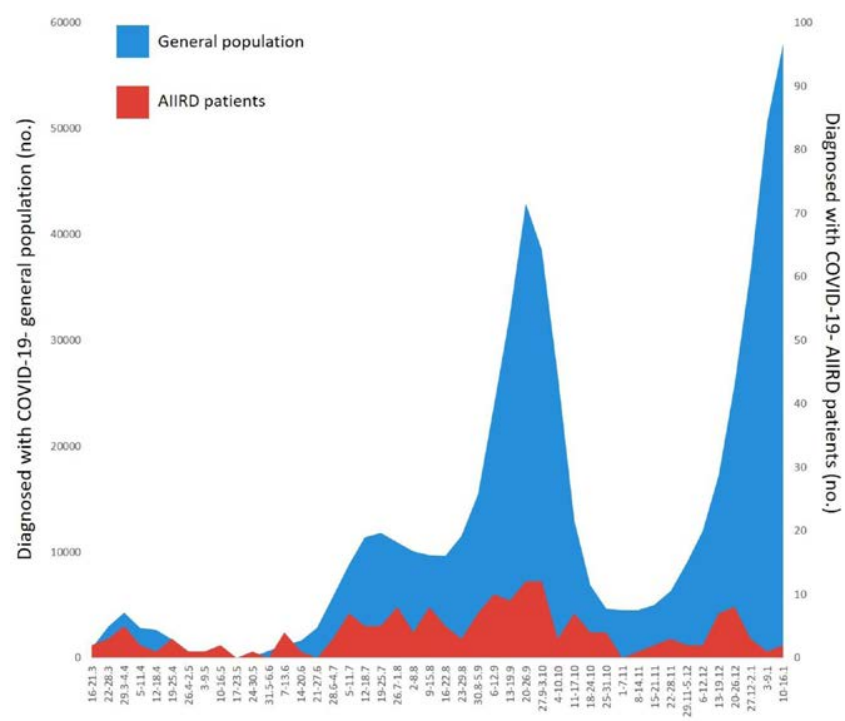

Figure 1.

Acknowledgements: Both first authors contributed equally to the manuscript. Disclosure of Interests: None declared. DOI: 10.1136/annrheumdis-2021-eular.2581

\section{POS1218}

SAFETY AND EFFICACY OF ANAKINRA IN SEVERE SARS-COV2 INFECTION (COVID19) AT A TERTIARY HOSPITAL

O. Rusinovich ${ }^{1}$, A. Mora ${ }^{2}$, E. Muñez ${ }^{3}$, L. Delgado Tellez de Cepeda ${ }^{3}$,

N. De la Torre ${ }^{1}$, M. Pavía ${ }^{1}$, J. Sanz ${ }^{1}$, M. Espinosa ${ }^{2}$, J. L. Andréu Sánchez ${ }^{1}$, J. Campos Esteban ${ }^{1} .{ }^{1}$ Hospital Universitario Puerta de Hierro Majadahonda, Rheumatology, Majadahonda, Spain; ${ }^{2}$ Hospital Universitario Puerta de Hierro Majadahonda, Internal Medicine, Majadahonda, Spain; ${ }^{3}$ Hospital Universitario Puerta de Hierro Majadahonda, Pharmacy, Majadahonda, Spain

Background: SARS-CoV-2 virus is a novel coronavirus that causes COVID-19 disease, which in its most severe form produces life-threatening atypical pneumonia and ARDS. Coronaviruses induce dysregulation of the immune system resulting in a cytokine storm syndrome with activation of the macrophage mediated mainly by IL-1 and IL- 6 . Although there is no specific treatment to date researchers have explored novel approaches through targeting both IL- 6 and $\mathrm{IL}-1$. Anakinra is a recombinant human $\mathrm{IL}-1$ receptor antagonist that prevents IL-1 $\beta$ and IL- $1 \alpha$ binding and therefore blocks signal transduction. Its high bioavailability, rapid action, relatively short half-life and good safety profile make it a promising drug

Objectives: Analyse the experience of administering Anakinra for severe forms of COVID19 in patients hospitalised at a tertiary hospital.

Methods: Retrospective single-center study in which all patients admitted for COVID-19 and treated with Anakinra from April 1st to the end of the 1st wave 
(July 2020) were included. Medical records were reviewed to collect demographic, clinical and lab test data, using Brescia-COVID respiratory severity scale, SaFi, CRP, Ferritin, LDH and lymphocytes. Variables were assessed at baseline, $72 \mathrm{~h}$ and 7 days after treatment initiation. Descriptive statistical analysis was performed, including a sub-analysis of patients who received anakinra as the only biological treatment.

Results: 54 patients were included, of which 37 male $(68.5 \%)$ with a median age of 69.5 years (36-94). Comorbidities were lung disease 14 pts $(25.9 \%)$, cardiovascular disease 39 pts (72.2\%), Diabetes Mellitus 11 pts (20.4\%), kidney disease and rheumatic disease each in 6 pts (11.1\%), and immunosuppression 13 pts (24.1\%). Each patient received a mean of 4.85 doses of anakinra $( \pm 3.96)$. Other therapies included low-dose steroids (70.3\%); high-dose steroids: $1 \mathrm{mg} / \mathrm{kg}(87 \%)$, bolus (24\%), Tocilizumab (57.4\%), Infliximab (24.1\%), Lopinavir/Ritonavir (48\%), Hydroxychloroquine (94.4\%), and Azithromycin (79.6\%). Mortality was $22 \%$ overall, $75 \%$ due to COVID19, $8.3 \%$ due to infectious complications and $16.7 \%$ due to non-infectious complications. In the group receiving Anakinra as only biological drug, mortality accounted for $17.9 \%$ of patients, $75 \%$ due to COVID19 and $25 \%$ to non-infectious complications. No adverse effects related to anakinra were observed.

\begin{tabular}{|c|c|c|c|c|c|c|c|}
\hline & \multicolumn{3}{|c|}{ General group $(n=54)$} & \multicolumn{3}{|c|}{$\begin{array}{l}\text { Group receiving anakinra as only } \\
\text { biological drug }(n=23)\end{array}$} & \multirow[t]{2}{*}{$\mathbf{P}$} \\
\hline & Baseline & After $72 \mathrm{~h}$ & After $7 d$ & Baseline & After $72 \mathrm{~h}$ & After $7 d$ & \\
\hline Brescia-COVID & $1.65(0.95)$ & $1.63(1.13)$ & $1.73(1.19)$ & $1.09(0.8)$ & $0.91(0.88)$ & $1.09(0.8)$ & \\
\hline Mean(SD) & $\begin{array}{c}\text { Values: } \\
0: 11.1 \% \\
\text { 1: } 31.5 \% \\
2: 42.6 \% \\
3: 53.7 \% \\
4: 3.7 \%\end{array}$ & $\begin{array}{c}\text { Values: } \\
\text { 0: } 16.7 \% \\
\text { 1: } 27.8 \% \\
2: 38.9 \% \\
3: 7.4 \% \\
4: 9.3 \%\end{array}$ & $\begin{array}{c}\text { Values: } \\
0: 7.9 \% \\
1: 52.6 \% \\
2: 18.4 \% \\
3: 7.9 \% \\
4: 13.2 \%\end{array}$ & $\begin{array}{c}\text { Values: } \\
0: 26.1 \% \\
1: 47.8 \% \\
2: 21.7 \% \\
3: 4.34 \% \\
4: 0 \%\end{array}$ & $\begin{array}{c}\text { Values: } \\
0: 39.1 \% \\
1: 34.8 \% \\
2: 21.7 \% \\
3: 4.34 \% \\
4: 0 \%\end{array}$ & $\begin{array}{c}\text { Values: } \\
0: 8.7 \% \\
1: 82.6 \% \\
2: 8.7 \% \\
3: 0 \% \\
4: 0 \%\end{array}$ & NS \\
\hline SaFi & $\begin{array}{c}222.60 \\
(115.2)\end{array}$ & $\begin{array}{c}240.51 \\
(117.6)\end{array}$ & $\begin{array}{c}250.95 \\
(102.6)\end{array}$ & $\begin{array}{c}306.35 \\
(124.7)\end{array}$ & $\begin{array}{c}316.04 \\
(129.8)\end{array}$ & $\begin{array}{c}300.36 \\
(135.4)\end{array}$ & NS \\
\hline Mean (SD) & $\begin{array}{c}\text { Values: } \\
>300: \\
25.9 \% \\
201-299 \\
: 14.8 \% \\
<201: \\
59.3 \%\end{array}$ & $\begin{array}{c}\text { Values: } \\
>300: \\
24.5 \% \\
201-299 \text { : } \\
26.4 \% \\
<201: \\
49 \%\end{array}$ & $\begin{array}{c}\text { Values: } \\
>300 \text { : } \\
34.2 \% \\
201-299 \text { : } \\
34.2 \% \\
<201: \\
31.6 \%\end{array}$ & $\begin{array}{c}\text { Values: } \\
>300 \text { : } \\
56,52 \% \\
201-299: \\
17.39 \% \\
<201: \\
26.1 \%\end{array}$ & $\begin{array}{c}\text { Values: } \\
>300 \text { : } \\
52.2 \% \\
201-299 \text { : } \\
21.7 \% \\
<201: \\
26.1 \%\end{array}$ & $\begin{array}{c}\text { Values: } \\
>300: \\
45.46 \% \\
201-299: \\
27.27 \% \\
<201: \\
27.27 \%\end{array}$ & \\
\hline $\begin{array}{l}\text { Lymphocytes, } \\
10^{\wedge} 3 / \text { microL } \\
\text { Mean (SD) }\end{array}$ & $\begin{array}{l}1.07 \\
(1.5)\end{array}$ & $\begin{array}{c}5.16 \\
(3.05)\end{array}$ & $\begin{array}{c}1.15 \\
(2.49)\end{array}$ & $\begin{array}{c}0.88 \\
(0.56)\end{array}$ & $\begin{array}{c}1.25 \\
(0.79)\end{array}$ & $\begin{array}{l}1.15 . \\
(2.4)\end{array}$ & NS \\
\hline $\begin{array}{l}\text { Ferritine, } \\
\mathrm{ng} / \mathrm{ml} \\
\text { Mean (SD) }\end{array}$ & $\begin{array}{l}1098.4 \\
(944.8)\end{array}$ & $\begin{array}{l}1080.23 \\
(873.9)\end{array}$ & $\begin{array}{r}1069.19 \\
(989.42)\end{array}$ & $\begin{array}{l}1112.76 \\
(621.80)\end{array}$ & $\begin{array}{c}903.25 \\
(385.49)\end{array}$ & $\begin{array}{c}704.14 \\
(261.86)\end{array}$ & NS \\
\hline $\begin{array}{l}\text { C-reactive } \\
\text { protein, } \\
\text { mg/L }\end{array}$ & $\begin{array}{c}38.78 \\
(37.58)\end{array}$ & $\begin{array}{l}21.46 \\
(20.17)\end{array}$ & $7(6)$ & $\begin{array}{c}50 \\
(6.38)\end{array}$ & $\begin{array}{l}34.67 \\
(23.3)\end{array}$ & $\begin{array}{c}19.96 \\
(28.92)\end{array}$ & NS \\
\hline Mean (SD) & & & & & & & \\
\hline $\begin{array}{l}\text { LDH, U/L } \\
\text { Mean (SD) }\end{array}$ & $\begin{array}{l}387.64 \\
(163.1)\end{array}$ & $\begin{array}{c}394.98 \\
(209.32)\end{array}$ & $\begin{array}{c}374.26 \\
(157.63)\end{array}$ & $\begin{array}{l}326.38 \\
(111.66)\end{array}$ & $\begin{array}{c}308 \\
(116.59)\end{array}$ & $\begin{array}{c}355 \\
(151.96)\end{array}$ & NS \\
\hline $\begin{array}{l}\text { Respiratory } \\
\text { improvement* }\end{array}$ & N/A & $20.37 \%$ & $51.85 \%$ & N/A & $30.43 \%$ & $69.5 \%$ & .007 \\
\hline $\begin{array}{l}\text { Lab test } \\
\text { improve- } \\
\text { ment }^{\star \star}\end{array}$ & N/A & $51.85 \%$ & $77.78 \%$ & N/A & $60.87 \%$ & $78.2 \%$ & NS \\
\hline
\end{tabular}

* SaFi normalised or increased $100 \mathrm{mmHg}$ or more ${ }^{\star \star}$ Improvement of 2 or more analytic variables

Conclusion: Anakinra in severe SARS-CoV-2 infection offers respiratory improvement and partial lab tests improvement. No adverse effects were observed. Acknowledgements: We wish to acknowledge Puerta de Hierro Majadahonda COVID19 task force and all the patients and staff affected by the pandemic. Disclosure of Interests: None declared

DOI: 10.1136/annrheumdis-2021-eular.2590

\section{POS1219 SARS-COV-2 VACCINE HESITANCY AMONG PATIENTS WITH RHEUMATIC AND MUSCULOSKELETAL DISEASES: A MESSAGE FOR RHEUMATOLOGISTS}

R. Priori ${ }^{1,2}$, G. Pellegrino $^{1}$, S. Colafrancesco ${ }^{1}$, C. Alessandri ${ }^{1}, F$. Ceccarelli ${ }^{1}$, M. DI Franco ${ }^{1}$, V. Riccieri ${ }^{1}$, R. Scrivo ${ }^{1}$, A. Sili Scavalli ${ }^{1}$, F. R. Spinelli ${ }^{1}$, F. Conti ${ }^{1}$. 'Sapienza University of Rome, Department of Clinical Internal, Anesthesiological and Cardiovascular Sciences, Rome, Italy; ${ }^{2}$ Saint Camillus International University of Health Sciences, Saint Camillus International University of Health Sciences, Rome, Italy

Background: Conflicting results have been published regarding the risk of infection with SARS-CoV-2 and development of severe COVID-19 among patients affected by rheumatic musculoskeletal diseases (RMDs). [1-4] Taking into account the lack of effective drugs to treat the COVID-19 and despite the burdensome and costly lockdown measures adopted to counteract the spread of SARS-CoV-2, effective and safe vaccines appear reasonably to be the best strategy for fighting the virus. [6] Before vaccines availability, several reports showed that a non-negligible proportion of subjects, among the general population or within specific categories, would have refused vaccination against COVID-19 once possible; $[6,7]$ data on vaccination hesitation among patients with RMD are not available yet.

Objectives: This study aimed to evaluate the attitude of patients with RMDs to vaccination against SARS-CoV-2 and explore the factors which may influence it. Methods: During the first weeks of Europe vaccination campaign, we proposed an online survey to Italian adult patients with RMDs followed up in the Rheumatology Unit. All patients fulfilled the most recent classification criteria for each disease. HCs were recruited using a "best friend" system. The informed consent was collected for all participants. The questionnaires included the following items: demographic features, presence of comorbidities, educational level, and ongoing therapy. The individual's perception of the COVID-19 vaccination, as well as the willingness to receive a COVID-19 vaccination with targeted questions was properly assessed. For the statistical analyses, Mann-Whitney and Chi-square tests were used. To account for baseline clinical differences among RMD-patients and controls, multivariable logistic regression analysis was used; covariates were selected according to a clinical criterion. The hypothesis that willingness for COVID-19 vaccine varied in specific subgroups of patients was tested using interaction terms at logistic regression analysis. All statistical tests were performed using the RStudio graphical interface and all tests were two-sided with a significance level set at $p<0.05$.

Results: We provided an online survey to 830 adult RMD-patients and 370 healthy controls (HCs). Overall, $626 \mathrm{RMD}$-patients and $345 \mathrm{HCs}$ completed the survey. Patients with RMDs were less willing to receive a COVID-19 vaccination compared to $\mathrm{HCs}$ (Odds Ratio (OR) $0.24,95 \% \mathrm{Cl} 0.17-0.34, \mathrm{p}<0.0001$ ) despite they perceived themselves as at higher risk both to get infected (OR 11.3, 95\% Cl 8 - 15.9, p<0.0001) and develop a severe COVID-19 (OR 11.06, 95\% Cl 7.8 - 15.6, $\mathrm{p}<0.0001)$ and even if they had been vaccinated for influenza and pneumococcus more frequently than controls $(\mathrm{OR} 1.6095 \% \mathrm{Cl} 1.18-2.16, \mathrm{p}=0.002 ; \mathrm{OR} 2.23,95 \%$ $\mathrm{Cl} 1.34-3.73, \mathrm{p}=0.002$ ). However, our results reveal that RMD-patients are more willing to change their minds if properly informed by the rheumatologist (OR 3.08 , $95 \% \mathrm{Cl} 2.19-4.34, \mathrm{p}<0.0001$ ) in comparison to controls.

Conclusion: The results of our study indicate for the first time that patients with RMDs are less willing to receive COVID-19 vaccination compared to the general population, despite perceiving themselves as at higher risk of getting infected with SARS-CoV-2 and develop severe COVID-19. However, our data underscored a meaningful aspect: patients with RMDs may change their attitude to COVID-19 vaccination if properly informed about risks and benefits by their trusted specialist.

The results of this study encourage the entire rheumatologist community to become more committed to patient education, increasing their willingness to COVID-19 vaccine, which is the most promising strategy to protect them from the virus.

References: 1]Favalli EG et al. Arthritis Rheumatol, 2020

[2] Fredi M, et al. Lancet Rheumatol, 2020

[3] Giardina F et al. Rheumatol Int 2021

[4] Pellegrino G et al. Clin Rheumatol 2020.

[5] Frederiksen LSF, et al. Front Immunol, 2020.

[6] La Vecchia C et al. Med Lav 2020.

[7] Qiao S, et al. medRxiv 2020.

Disclosure of Interests: None declared

DOI: 10.1136/annrheumdis-2021-eular.2622

\section{POS1220 \\ PREGNANT AND POSTPARTUM WOMEN WITH AUTOIMMUNE RHEUMATIC DISEASES AND COVID-19: A CASE SERIES}

R. A. Rodriguez Chavez ${ }^{1}$, C. M. Skinner Taylor ${ }^{1}$, L. Pérez Barbosa ${ }^{1}$, G. Figueroa-Parra', J. E. Compeán-Villegas'1, L. G. Espinosa Banuelos ${ }^{1}$, R. Moyeda Martinez ${ }^{1}$, A. Y. Lujano Negrete ${ }^{1}$, A. Cárdenas ${ }^{1}$, D. Á. GalarzaDelgado'. ${ }^{1}$ Hospital Universitario Dr. José Eleuterio González, Rheumatology Service, Monterrey, Mexico

Background: Pregnant women represent a high-risk population during the COVID-19 pandemic. The main cause of maternal deaths in Mexico during 2020 was COVID-19 with 191 (21.2\%) deaths registered until December 2020. The age group most affected was 30 to 34 years. Women during their third trimester and during puerperium were the most affected. Information regarding pregnant and postpartum women with autoimmune rheumatic diseases remains scarce.

Objectives: The aim of this study was to describe a COVID-19 case series from a clinic of pregnancy and rheumatic diseases.

Methods: We conducted a descriptive, retrospective study in patients from the clinic of pregnancy and rheumatic diseases of the University Hospital "Dr. Jose Eleuterio Gonzalez" in Monterrey, Mexico. Pregnant patients with RD and documented COVID-19 between March and November 2020 were included. Demographic and clinical features were obtained. Results are shown in descriptive statistics. 